\title{
How do migrants save? Evidence from the British Household Panel Survey on temporary and permanent migrants versus natives
}

\author{
Giuseppe De Arcangelis ${ }^{1 *}$ and Majlinda Joxhe ${ }^{2}$
}

\author{
${ }^{*}$ Correspondence: \\ giuseppe.dearcangelis@uniroma1.it \\ ${ }^{1}$ Dept. of Social Sciences and \\ Economics, Political Science \\ Building CU002 - room 103bis, \\ Sapienza University of Rome, P.le \\ Aldo Moro, 5 00185, Rome, Italy \\ Full list of author information is \\ available at the end of the article
}

\begin{abstract}
This paper investigates the saving behavior of migrants in the UK across different dimensions, i.e., comparing temporary versus permanent migrants and migrants versus natives. Established theoretical predictions show that migrants save more when they plan to stay in the destination only temporarily as target savers. Our empirical evidence takes into account the contemporaneous choice of savings and remittances. Moreover, when comparing the saving profiles of both natives and migrants, we uncover the weight of observable socio-economic characteristics other than income and wealth. We use the British Household Panel Survey for the period 1991-2008. The estimation results confirm that temporary migrants have a propensity to save 26 per cent higher than permanent migrants in UK. We also introduce an index of financial capability adjusted for income as an explanatory variable and, when employing the Blinder-Oaxaca decomposition for the Tobit model of saving choice, migrants are more affected by observable social-economic characteristics than natives.
\end{abstract}

JEL classification: F22; D91; C40

Keywords: Temporary migration; Savings; Remittances; Blinder-Oaxaca decomposition

\section{Introduction}

The economic literature on migration investigates earnings and employment status as good long-run indicators for the economic integration of migrants (Borjas 1995; Constant and Zimmermann 2005; Peri 2012). Meanwhile, other authors (e.g., Bauer and Sinning 2011) argue that the level of private savings also plays an important role since a higher propensity to save and invest financially in the destination country represents a strong signal of social assimilation.

However, migrants are heterogeneous in terms of their expected length of stay - temporary (or circular) versus permanent migrants - and their ability or willingness to save may be different along this dimension.

The length of stay of migrants have relevant consequences on national savings when temporary and permanent migrants have different attitudes to savings in the destination country. Permanent migrants are expected to save and invest in the destination country as a typical life-cycle decision, and their contributions will return to them when retiring in

(C) 2015 De Arcangelis and Joxhe; licensee Springer. This is an Open Access article distributed under the terms of the Creative Commons Attribution License (http://creativecommons.org/licenses/by/4.0), which permits unrestricted use, distribution, and reproduction in any medium, provided the original work is properly cited. 
the same destination country. From the point of view of the inter-temporal computations, permanent migrants and natives are not different, and the only leakage from the national savings may be represented by the money sent to the origin country for reasons discussed in the literature on remittances (see Rapoport and Docquier 2006). Temporary migrants instead do not have any incentive to save and invest in the destination country; however, they actually do, especially with compulsory payments to national pension systems, which are difficult to withdraw or carry back to the origin country. ${ }^{1}$

Besides the effects on the domestic labor markets, the contribution to national savings, foregone for migrants that decide to go back to the home country, is an additional reason why governments in destination countries tend to prefer temporary versus permanent migrants. For instance, countries like Germany or UK are moving toward a system that regulates the stock of immigrants preferring short-term visas.

However, recent evidence shows that the decision to stay permanently in the destination country may come with life experience, and many migrants that started with short-run projects ended up spending their retirement in the receiving country. This is particularly important in the next decades when the generations of migrants that arrived in richer European countries during the 80s and 90s (or even before) will reach retirement age.

Germany, is an example of the importance of private savings for the future economic situation of immigrants (see Bauer and Sinning 2011). In the 1960s and 1970s, a large number of "temporary guest workers", mainly from Southern Europe, migrated to Germany. Most of them stayed in Germany permanently (Bauer and Zimmermann 2000). The savings propensity and the resulting wealth position of this group of immigrants may become an important factor for the German pension system because about 1.5 million immigrants in Germany will reach retirement age within the next 15 years (Bauer and Sinning 2011).

In this study, one objective is to uncover the difference in saving attitudes between temporary and permanent migrants for the UK so as to test and quantify the gap and to compare it with the natives.

In the migration literature, the length of stay has been considered an important determinant of the saving behavior among migrants. For instance, Piore (1979) talks of target-earning migrants as individuals saving money abroad with an investment goal in their home country, like purchasing new dwellings. Temporary migrants may be associated with target earners whose primary motivation for going and working abroad is to save enough money in order to start a small business at home or purchase either financial or non-financial assets upon return (Djajic and Michael 2009).

Mesnard (2004) provides a model of the target-saving motive in an analysis of optimal return decisions where temporary migrants are assumed to have borrowing constraints in their country of origin. She concludes that once a migrant achieves the goal of accumulating a certain stock of assets abroad, she or he returns to the home country and invests. In this perspective, the optimal migration duration coincides with the time needed to attain the savings target.

Djajic and Milbourne (1988), Dustmann (1997, 2003), and Kirdar (2009) take a different stand and emphasize the utility-maximizing approach to saving and return decisions, where the optimal timing of return is determined by comparing the costs and benefits of staying longer abroad. Yang (2006) highlights the differences between the target-earning and life-cycle motivations of temporary migrants, emphasizing that if the aim is to attain 
a certain level of savings, the improved conditions in the origin country - such as an increase in wages - should entail shorter overseas stays.

The economic literature refers mainly to three different types of saving behaviors for migrants that are closely linked to the remitting choice.

Firstly, some authors emphasize that the length of stay may affect the level of remittances, but not savings. Merkle and Zimmermann (1992) found that the planned duration of the stay in the host country is a significant determinant of remittances, but they show that there is no significant effect for savings. Dustmann and Mestres (2010) investigates the saving plans and the assets holdings of migrants and shows that immigrants with temporary return plans place a higher proportion of their savings in the home country as remittances, with little effect on the national savings of the host economy. The magnitude and the share of assets accumulated at home (including the housing value) are larger for the immigrants who consider migration as temporary. Notwithstanding this effect on remittances, he finds no evidence that the temporary migrants save more than the permanent ones.

Secondly, other contributions emphasize how savings are as important as remittances, and, notwithstanding the direction, remittances (and the relative decision) may be considered as a form of savings. When sending money home, temporary migrants are engaging in a sort of precautionary savings, although accumulated in their home country, and remittances have to be considered and investigated as a type of saving decision.

Indeed, many studies have tested the theoretical hypothesis of the motives for remitting other than the insurance-saving motive and found little statistical evidence on alternative drivers. For instance, Stark and Lucas (1988) underline that the motive to remit may be pure altruism, but finds empirical evidence for the theory of pure self-interest using data on Botswana. He concludes that altruism alone does not appear to be a sufficient explanation on the motivation to remit.

Thirdly, other studies show that differences in saving patterns and in the wealth position may be caused by differences in earnings, which can be related to differences in socio-economic characteristics among migrants (cultural background, different skills, etc). Carroll et al. (1994) find that the saving patterns of immigrants are significantly different across countries of origin. There are two effects that might contribute to the saving differentials among different groups. The first one is the immigration effect that corresponds to an effect relevant for all groups of immigrants; the second is the cultural effect and is referred to the immigrant's origin country characteristics (or to the characteristics of the ethnic group). Moreover, the saving patterns of immigrants do not match up with the saving patterns of the origin countries in aggregate data. Indeed, using data from the US census from 1980-1990, they find that the immigrants from countries with high saving rates, such as Japan, Korea, Taiwan, do not have higher saving rates than the other migrants.

Another important question regards the difference in savings behavior between migrants and natives. Cobb-Clark and Hildebrand (2003) argue that individuals may retain some social norms about inter-generational transfers; this can influence the amount of expected inherited wealth and consequently the post-migration savings propensity. The difference in these social norms between origin and destination countries may lead to differences in the savings behavior between migrants and natives, as well as within the heterogeneous immigrant population. Using data from the Survey of Income 
Program Participation, Cobb-Clark and Hildebrand (2003) show that foreign-born households in the US are less wealthy than their US-born counterparts. Their findings indicate that the diversity in wealth levels can be attributed primarily to differences among the origin regions rather than to differences among entry cohorts.

The purpose of this study is twofold. First, we provide an empirical analysis of the savings behavior of the foreign-born by using the British Household Panel Survey (BHPS) during the period 1991-2008. The main aim is to assess whether migrants are engaged in a form of saving activity and give evidence on whether the rate of savings is different between temporary and permanent migrants. The theoretical reference is the model by Galor and Stark (1990), where under a positive probability of return, the migrants would save more, and in the case they do not return, the total wealth of the migrants is higher than for the natives.

Our study performs different estimation methods in order to verify the theoretical prediction of higher savings for the temporary immigrants. We have underlined how the choice to save is closely linked to the decision to remit. Hence, the binary choice of saving or not saving is modeled together with the choice of remitting or not remitting in a bivariate dynamic structure. Moreover, the decision to save or to remit is censored, and we deem that a Tobit dynamic bivariate model is the most appropriate estimation choice. Estimation results show that the amount of savings for temporary migrants is higher by around 26 percent with respect to the permanent migrants.

The second aim of the study is to compare the saving behavior of migrants with that of natives. We propose an index of financial (in)capability adjusted for income along the lines of Taylor et al. (2011) and perform a Blinder-Oaxaca decomposition in order to establish what is the origin of the difference between natives and migrants, i.e., which socio-economic characteristics (besides income and wealth) can explain that difference. ${ }^{2}$

We find that, although the probability to save does not depend on the temporary nature of migration, there is a significant increase in the amount of savings in the case where the migrant is staying temporarily in the country. The amount of savings is 26 percent higher for temporary migrants. Another interesting result comes from our nonlinear decomposition model a la Blinder-Oaxaca. The decomposition shows that the saving behavior differs between migrants and natives because of both socio-economic characteristics (e.g., education level, occupational status, age, etc.) and behavioral differences (i.e., propensities to save), but with a higher weight for socio-economic characteristics when introducing the index of financial (in)capability - from 45 percent to over 95 percent.

The contribution to the existing literature is twofold. First, this is the first study, to our knowledge, that attempts to compare the saving rates of temporary and permanent migrants when including endogenously the remitting behavior with a bivariate dynamic model. Our results allow for providing empirical evidence on the economic integration of migrants in UK using savings rather than earnings or employment status, similar to how Bauer and Sinning (2011) explores the savings of migrants using the GOESP database for Germany.

Second, we study differences in the savings rates between migrants and natives using a (Tobit) nonlinear decomposition model as an extension of the original Blinder-Oaxaca decomposition, following the similar methodology proposed by Bauer and Sinning (2010).

Section 2 describes the data and the hypothesis on which the empirical analysis is based. In Section 3, we investigate the saving behavior of temporary versus permanent migrants 
by means of a dynamic bivariate probit model in order to model contemporaneously savings and remittances. Section 4 presents more evidence on the difference between temporary and permanent migrants and also offers an analysis of the differences between natives and migrants in terms of saving choices with the Blinder-Oaxaca decomposition. Section 5 concludes.

\section{Data and hypothesis}

The British Household Panel Survey (BHPS) began in 1991 and was designed as an annual survey of the adult population (see Taylor et al. 2002). It is a nationally representative sample of more than 5,000 households, totaling approximately 10,000 individual interviews. It is a survey in which all adult members of each household are available to be interviewed each year. The primary purpose of BHPS data is to collect detailed information on demographics and socio-economic behavior of the UK households, such as household's consumption, income, geographic mobility, etc. The total person-year observations are 180,543, after excluding for non-response and non-valid values of the variables. The BHPS also comprises foreign-born individuals and households, and this is the sub-sample that we use for the empirical investigation.

We identify immigrants by their place of birth, limit the analysis to both males and females older than 16, and use data on occupation, education, and household income. These restrictions bring the sample size of migrants to an unbalanced panel of 7,709 person-year observations equal to 4.3 percent of the total sample. The sample size of natives amounts to 171,642 person-year observation.

In the migrants' sample, households of at least couples are 70 percent; males are 58 percent. In terms of employment status, 56 percent of the sample is employed, and around 11 percent declares to be self-employed, confirming that the share of the self-employed is relatively high among migrants in developed countries (see for instance Mesnard 2004), this also being a source of income uncertainty.

In terms of education attainment, a share of 13 percent has finished secondary school, and only 24 percent of individuals have no qualification. Meanwhile around 25 percent have finished college or obtained a University degree.

One of the aims of the study is to test whether the saving behavior changes with different migration plans and to verify if the temporary nature of migration affects the savings decisions.

In order to test this hypothesis, at first we need to identify temporary and permanent migrants in the panel. In fact, in the BHPS, the response status - reporting whether the household was found absent or did not respond to (some of) the following waves and why that happened - is very informative. The survey records not only as missing the household that was not interviewed but also the reason of the non-response. In particular, the value Outside UK allows us to identify whether the individual is out of the panel (attrition) and outside the country. When the interviewee is foreign born, then we can identify as temporary migrants all of those who are recorded as out of the country for some part of the sample. ${ }^{3}$ The number of identified temporary migrants is equal to 144 .

Another focus of the empirical analysis is to show drivers of the saving behavior among migrants - whether or not an individual saves from his current income and how much and between migrants and natives - whether the level of savings (as a fraction of income) is associated to the same socio-economic variables and with the same propensities. The 
other relevant feature, still closely connected to the saving behavior, is the amount of remittances.

Some of the questions in the BHPS allow to obtain a good proxy of savings and remittances for migrants.

In fact, in each wave, any individual is asked "Do you save any amount of your income for example by putting something away now and then in a bank, building society, or Post Office account other than to meet regular bills?". If the respondent replies positively, then he or she is asked "About how much on average do you manage to save a month?". The first question identifies the proportion of the savers in the sample and the second the average amount of monthly savings.

In the BHPS, each individual is also asked: "Do you send or give money to anyone who does not live here?". The answer could be labeled as remittances for the purpose of our analysis.

A full description of the variables is contained in Table 1.

Table 2 reports the descriptive statistics for natives and for all the migrants. We ought to notice that the propensity and the amount of savings of migrants strongly depends on the general economic conditions. Indeed, migrants are usually hit hard by downturns of the economy and by adverse shocks in the labor market. Figure 1 depicts the relationship between the unemployment rate in the UK and the amount of savings of the foreignborn for the period 1991-2008. The graph shows a strong negative correlation; meanwhile, Figure 1(a) shows a very similar trend between household income and the amount saved in the same period.

Some evidence is clear already from these descriptive statistics. For instance, 39 percent of the migrants and 42 percent of natives declare to save from their current income, but the average amount of savings per month is higher (although not statistically significant) for migrants, $£ 167.54$ versus $£ 157.17$ respectively.

Table 3 reports detailed statistics on social and economic characteristics of migrants, separating temporary from permanent foreign-born residents. In terms of monthly savings, temporary migrants show a higher average, although not significantly different around $£ 60$ versus $£ 58$ - but permanent migrants save more and hold a higher percentage of assets. The extensive margin of remitters is higher for permanent migrants, i.e., only 5 percent of temporary migrants declare to send remittances versus 24 percent among permanent residents. Figure 2(a) shows the general trends of migrants' savings and remittances for all the years in our panel, whereas Figure 2(b) shows the same trends but distinguishes between temporary and permanent migrants.

Indeed, in the following Section 3, we take into account the joint decision of saving and remitting by the migrants.

The comparison between natives and migrants is instead confined to Section 4 .

\section{Savings and remittances of temporary vs. permanent migrants}

Galor and Stark (1990) have analyzed the differences in savings between natives and migrants by employing an overlapping generation framework. They show that migrants should save proportionally more than natives if they face a positive probability of return migration. In fact, this result is consistent with the life-cycle theory of consumption when migrants expect a drop in future income that is higher than for natives. 
Table 1 Variable description: BHPS 1991-2008

\begin{tabular}{|c|c|c|}
\hline Variables & Categories & Description \\
\hline \multicolumn{3}{|l|}{ Dependent variables } \\
\hline Saver & Binary & Declare to save from Current Income: $1=$ Yes; $0=$ No \\
\hline Remitter & Binary & Declaring to send money to residents abroad $1=\mathrm{Yes}, 0=\mathrm{No}$ \\
\hline Amount Saved & Continuous & Amount saved each month from Current Income \\
\hline Remittances & Continuous & Amount of Remittances send per month \\
\hline Index of Financial Incapability & Continuous & Index $[-1 ; 1] 1=$ Low Capability; $-1=$ High Capability \\
\hline \multicolumn{3}{|l|}{ Socio-Demographic Controls } \\
\hline \multicolumn{3}{|l|}{ Individual level } \\
\hline UK-Born & Binary & Dummy Variable: $1=$ Born in UK, 0=Otherwise \\
\hline Age & Continuous & Working Age for the whole Sample : 18-65 Years \\
\hline Male & Binary & Dummy variable: $1=$ Male; $0=$ Female \\
\hline Married & Binary & Dummy variable: $1=$ Married or living in couple; $0=$ otherwise \\
\hline Employed & Binary & Dummy variable: $1=$ Yes $; 0=$ No \\
\hline \multirow[t]{3}{*}{ Education Level } & Binary & Dummy variables for: 'No Qualification', 'O Level', \\
\hline & & 'No College Degree' 'University Degree' \\
\hline & & Reference Category: 'College Degree' \\
\hline \multicolumn{3}{|l|}{ Household level } \\
\hline Household Type & Binary & Couple $=1 ;$ Single $=0$ \\
\hline Number of Children & Ordinal & Number of children in the Household [0-9] \\
\hline \multirow[t]{2}{*}{ Net Household Income } & Continuous & Yearly Household Income deflated by 2005 CPI \\
\hline & & (divided by 100) and divided by the household size \\
\hline Household Owner & Binary & Head of the household is the ower of the house $1=$ Yes; $0=$ No \\
\hline Mortgage & Binary & The Household has mortgage for the house $1=$ Yes; $0=$ No \\
\hline \multicolumn{3}{|l|}{ Derived variables } \\
\hline Temporary & Binary & Migrant staying temporary in UK \\
\hline Holding Assets & Continuous & Declaring on holding financial assets \\
\hline \multicolumn{3}{|l|}{ Financial evaluation } \\
\hline Financial Situation & Binary & Financial situation: Alright or Difficult \\
\hline \multirow[t]{2}{*}{ Financial Expectation } & Binary & Financial Expectation for the next year: \\
\hline & & Better, Worse or the Same \\
\hline \multirow[t]{3}{*}{ Financial changed } & Binary & Financial Situation changed with respect to last year: \\
\hline & & Earnings Increased, Earning Decreased, \\
\hline & & Life is more expensive, Life is less expensive \\
\hline \multirow[t]{4}{*}{ Regional Dummies } & Binary & Dummy variables for 'London', 'South-East', 'South-West', \\
\hline & & 'East of England', 'East Midlands', 'West Midlands', \\
\hline & & 'Yorkshire', 'North-East', 'North-West', 'Scotland'; \\
\hline & & Reference category: 'Wales' \\
\hline Yearly Dummies & Binary & Dummy variables for years 1990-2008 \\
\hline
\end{tabular}

The same reasoning applies when considering different categories of migrants, and the planned duration of the migration project may affect their saving decisions.

One of the purposes of this study is to test empirically this theoretical claim by making use of the long panel of micro data contained in the BHPS for the years 1991-2008. In particular, we want to show that the propensity of saving is different between temporary and permanent migrants. Additional evidence is also provided in Section 4. As explained below, we use a bivariate dynamic model in order to endogenize another important saving-like choice of migrants, i.e., remittances. 
Table 2 Summary statistics: BHPS 1991-2008

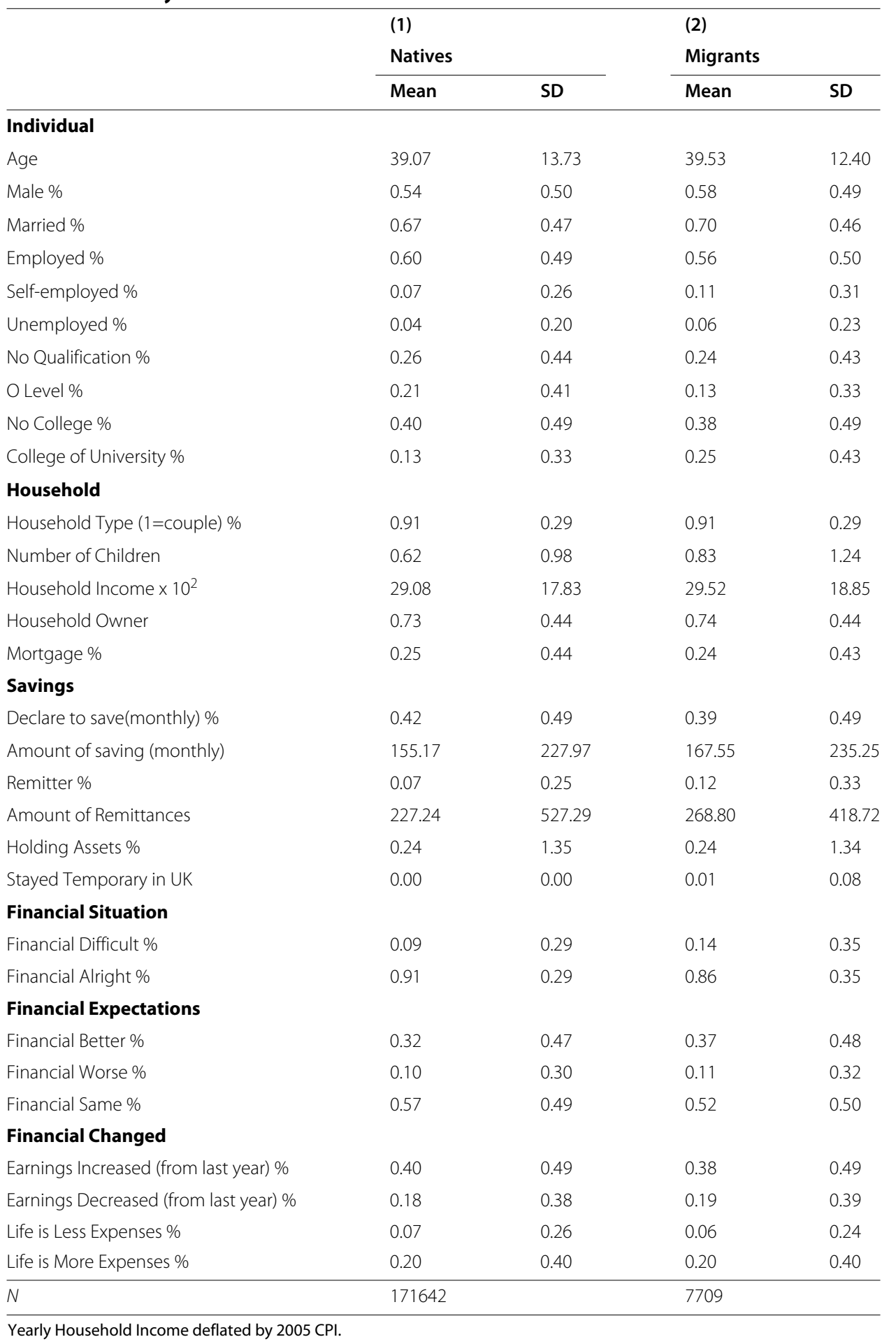

\subsection{A bivariate dynamic probit model for saving and remittances}

Evaluating the saving behavior of migrants without accounting for the endogenous effect of remittances is misleading. 
(a) Savings and Unemployment

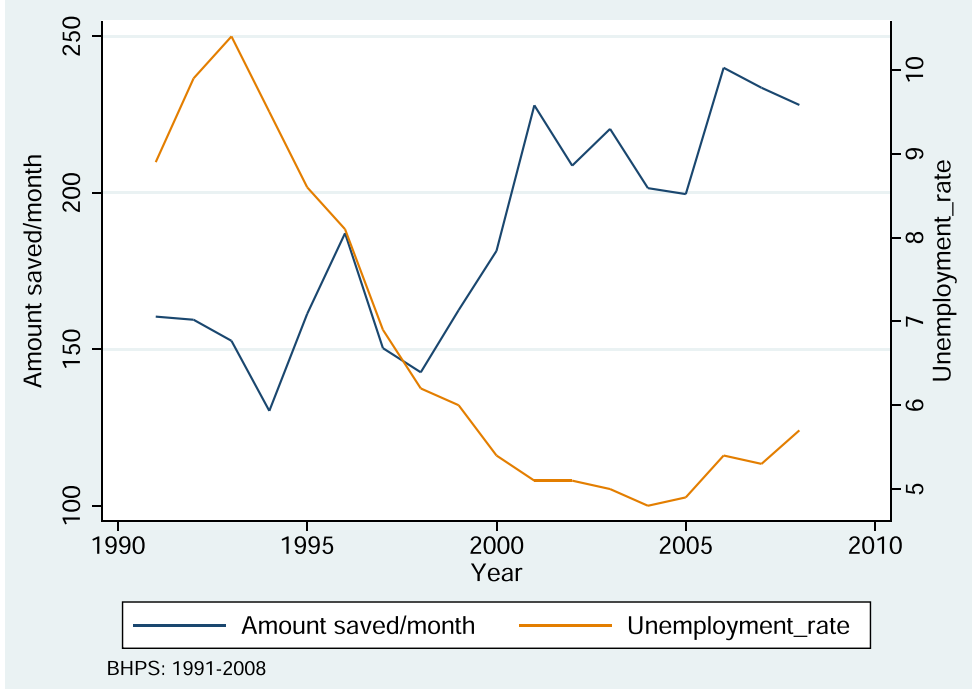

(b) Saving and Household Income

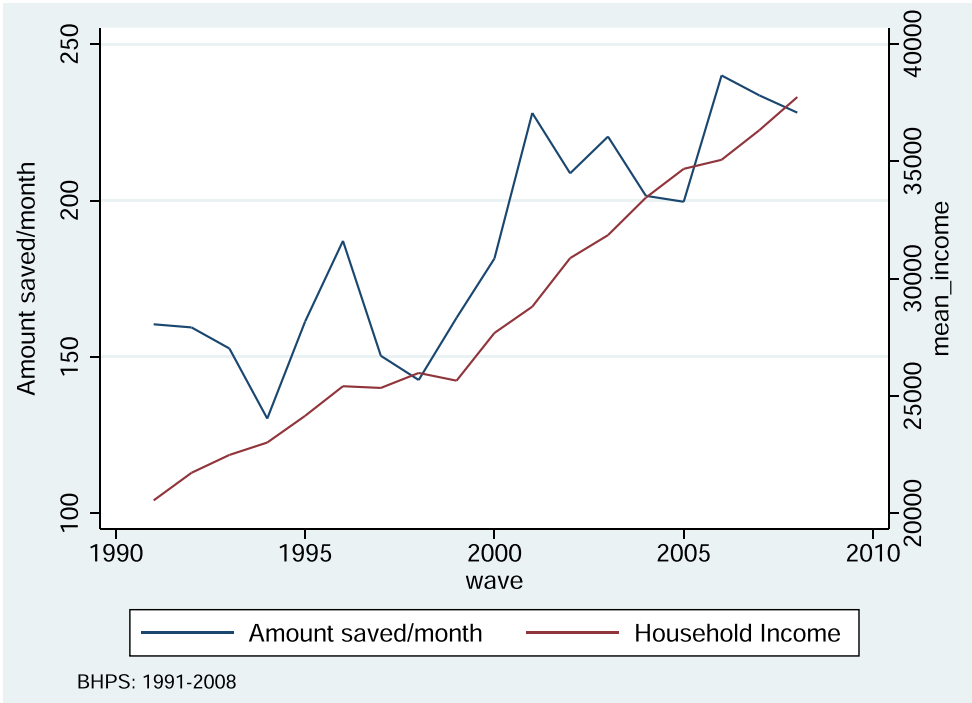

Figure 1 Savings, income and unemployment for migrants (1991-2008). (a) Savings and unemployment. (b) Saving and household income.

Differently from natives, migrants may save (e.g., put some money in their bank account for precautionary reasons), but at the same time, they send their savings home as remittances. The endogeneity of remittances would cause biased and inconsistent estimates of the parameters (and of their standard errors) when assessing the propensity to save.

To address the issue of interrelated dynamics of savings and remittances, we use a bivariate dynamic probit model with random effects where the two dependent variables represent the dichotomic choice of saving or not and of sending money home or not. This model also allows for correlated unobserved heterogeneity and accounts for the initial conditions of the two processes. We follow Alessie et al. (2004) and a recent application proposed by Devicienti and Poggi (2011). 
Table 3 Summary statistics: temporary and permanent migrants

\begin{tabular}{llllll}
\hline & \multicolumn{2}{c}{ Temporary } & & \multicolumn{2}{c}{ (2) } \\
\cline { 2 - 3 } \cline { 5 - 6 } & Mean & SD & & Mean & SD \\
\hline Age & 31.14 & 12.26 & & 39.57 & 12.38 \\
Male \% & 0.45 & 0.50 & & 0.58 & 0.49 \\
Married \% & 0.34 & 0.48 & & 0.70 & 0.46 \\
Employed \% & 0.52 & 0.51 & & 0.56 & 0.50 \\
No Qualification & 0.27 & 0.45 & & 0.24 & 0.43 \\
O level & 0.18 & 0.39 & & 0.13 & 0.33 \\
No College & 0.23 & 0.42 & & 0.38 & 0.49 \\
University Degree & 0.32 & 0.47 & & 0.25 & 0.43 \\
Declare to save (monthly) \% & 0.39 & 0.49 & & 0.39 & 0.49 \\
Amount of saving (monthly) & 59.89 & 168.88 & & 58.43 & 160.20 \\
Remitter \% & 0.05 & 0.21 & & 0.12 & 0.33 \\
Amount of Remittances & 250.00 & 430.80 & & 268.90 & 419.84 \\
Holding Assets \% & 0.07 & 0.24 & & 0.24 & 1.35 \\
Duration of Migration & 20.26 & 10.66 & & 24.72 & 13.11 \\
\hline$N$ & 144 & & 7665 & \\
\hline
\end{tabular}

Source: British Household Panel Survey (1991-2008).

All monetary variables are deflated by $2005 \mathrm{CPI}$

For the individual $i$ declaring to save from his current income and sending money home, the following equations are used to specify the choices at each time $t$ :

$$
\begin{aligned}
& y_{s, i, t}=\beta_{s} x_{i, t}+\lambda_{s, s} y_{s, i, t-1}+\lambda_{s, r} y_{r, i, t-1}+\alpha_{s, i}+u_{s, i, t} \\
& y_{r, i, t}=\beta_{r} x_{i t}+\lambda_{r, s} y_{s, i, t-1}+\lambda_{r, r} y_{r, i, t-1}+\alpha_{r, i}+u_{r, i, t} \\
& y_{j, i, t}=\left\{\begin{array}{l}
1 \text { if } z_{i, t}>0 \\
0 \text { if } \text { else }
\end{array}\right\} \quad \text { for } z=s, r ; t=1,2, \ldots T
\end{aligned}
$$

The dependent variables are the two dummy indicators: $y_{s, i, t}$ is equal to one if the individual $i$ declares to save from his current income at time $t$ (i.e., positive level of declared savings by individual $i, s_{i, t}>0$ ), zero otherwise; and $y_{r, i, t}$ is equal to one if $i$ is sending money home at time $t$ (i.e., positive level of declared remittances by individual $i, r_{i, t}>0$ ), zero otherwise. In the model represented by Equations (1)-(3), $x_{i, t}$ is a vector of control variables (not necessarily dichotomic), assumed to be strictly exogenous, and $\beta_{s}$ and $\beta_{r}$ are the two vectors of parameters of interest to be estimated. ${ }^{4}$

The error terms $u_{s, i, t}$ and $u_{r, i, t}$ are assumed to be independent over time and to follow a bivariate normal distribution, with zero means, unit variances and cross-equation covariance $\rho_{u}$. The model also includes individual random effects, $\alpha_{s, i}$ and $\alpha_{r, i}$, following a bivariate normal with variances $\sigma_{\alpha, s}$ and $\sigma_{\alpha, r}$ and covariance $\rho_{\alpha}$. We assume that $\left(\alpha_{s, i}\right.$, $\left.\alpha_{r, i}\right),\left(u_{s, i, t}, u_{r, i, t}\right)$ and $x_{i t}$ are orthogonal. ${ }^{5}$

The main advantages of multivariate dynamic random-effects models are their ability to distinguish between unobserved heterogeneity (random effects) and state dependence (the lagged dependent variable). It allows contemporaneous savings to be partly explained by the remittances at $t-1$ (the lagged state dependent variable) but also enables controlling for the contemporaneous spillover effects between the two states because $\rho_{\alpha} \neq 0$. 
(a) Savings and Remittances Migrants

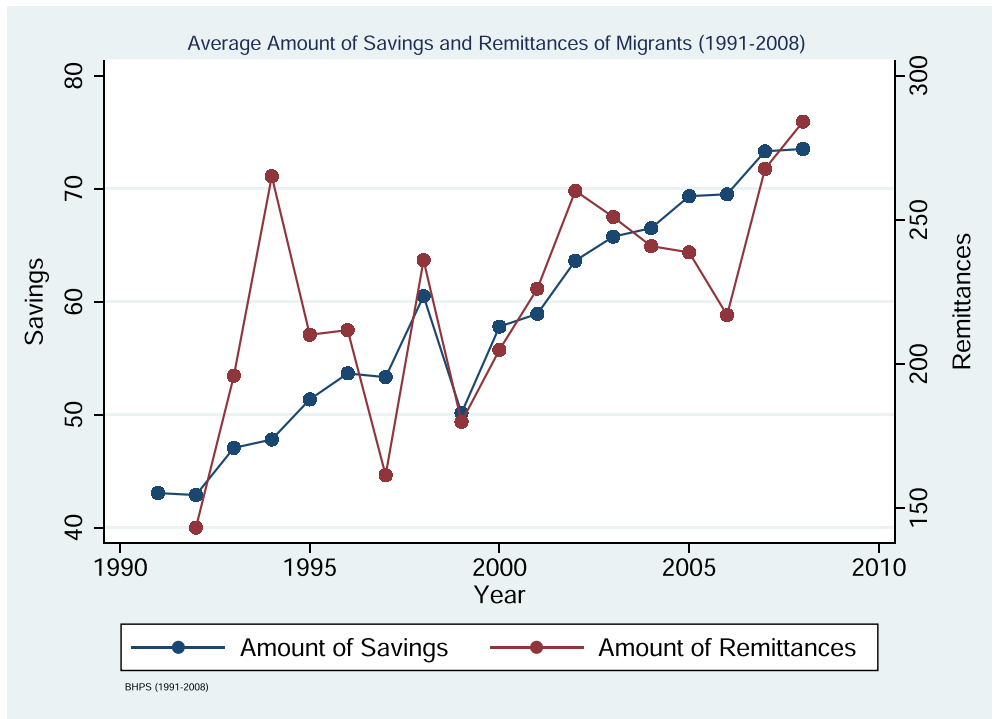

(b) Permanent and Temporary Migrants

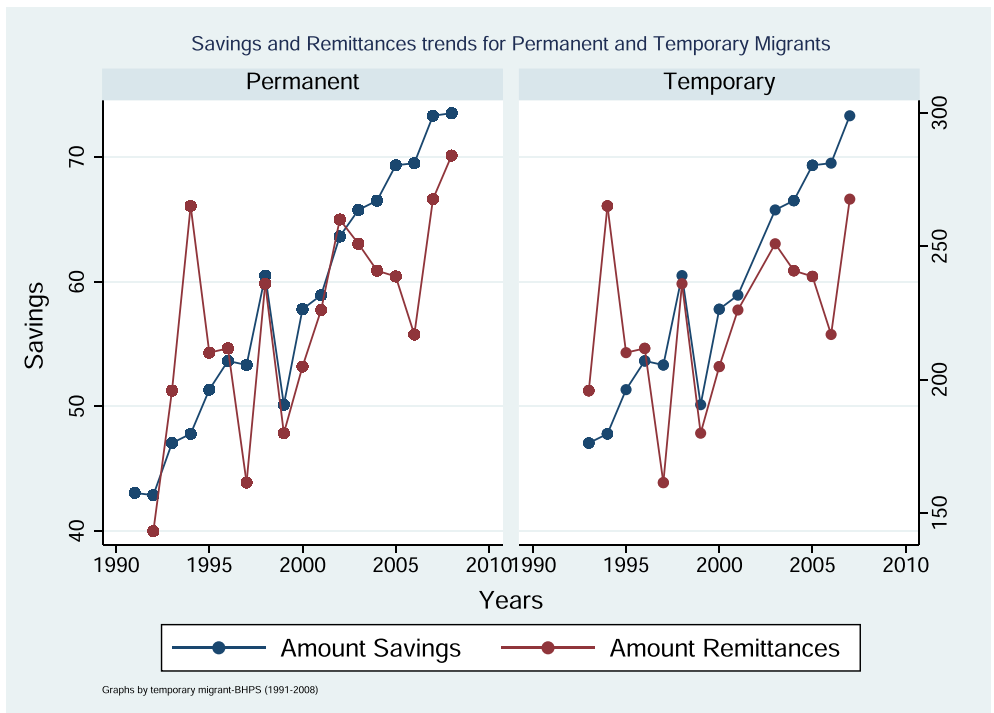

Figure 2 Savings and remittances trends (1991-2008). (a) Savings and remittances migrants. (b) Permanent and temporary migrants.

The parameters in the vectors $\beta$ 's represent the marginal effects of the various independent variables. The main coefficients of interest are related to the marginal effects of the following independent variables: the nature of the migration (dummy variable $=1$ if the migrant is temporary) and ethnicity (dummy variable $=1$ if individual $i$ is born in UK). Several other factors that may influence the saving behavior and the other control variables are: gender (male), marital status (married), household type (single), mean household income (net household income/household members), owners of real estate (household owner), and amount of financial assets; we also include some linear and nonlinear effects (age and age squared). We include three dummy variables to distinguish the occupational 
status of the individuals (employed, self-employed, unemployed), four dummy variables for the level of education (O level, no college, college and university degree). Yearly and regional dummies are included in order to account for the unobserved heterogeneity due to time and space.

\subsection{The initial conditions problem and the estimations results}

The first results of the pooled bivariate model are shown in Table 4.

The results of the pooled bivariate model show a very high significant state dependence between the two stati, saving and remitting. It is easy to underline that being a saver at $(t-1)$ increases the probability of engaging in a saving activity at time $t$ at 1 percent significance, but the status of remitter at $(t-1)$ decreases this probability.

The results shown in Table 4 are biased and inconsistent estimates when the unobserved heterogeneity is correlated with the lagged dependent variables.

In particular, the coefficients produced by the pooled estimation of our bivariate model are biased upward and overestimate the effects of the independent variables on both probabilities of saving and remitting. The overestimation of the parameters is due

Table 4 Bivariate dynamic model for savers and remitters

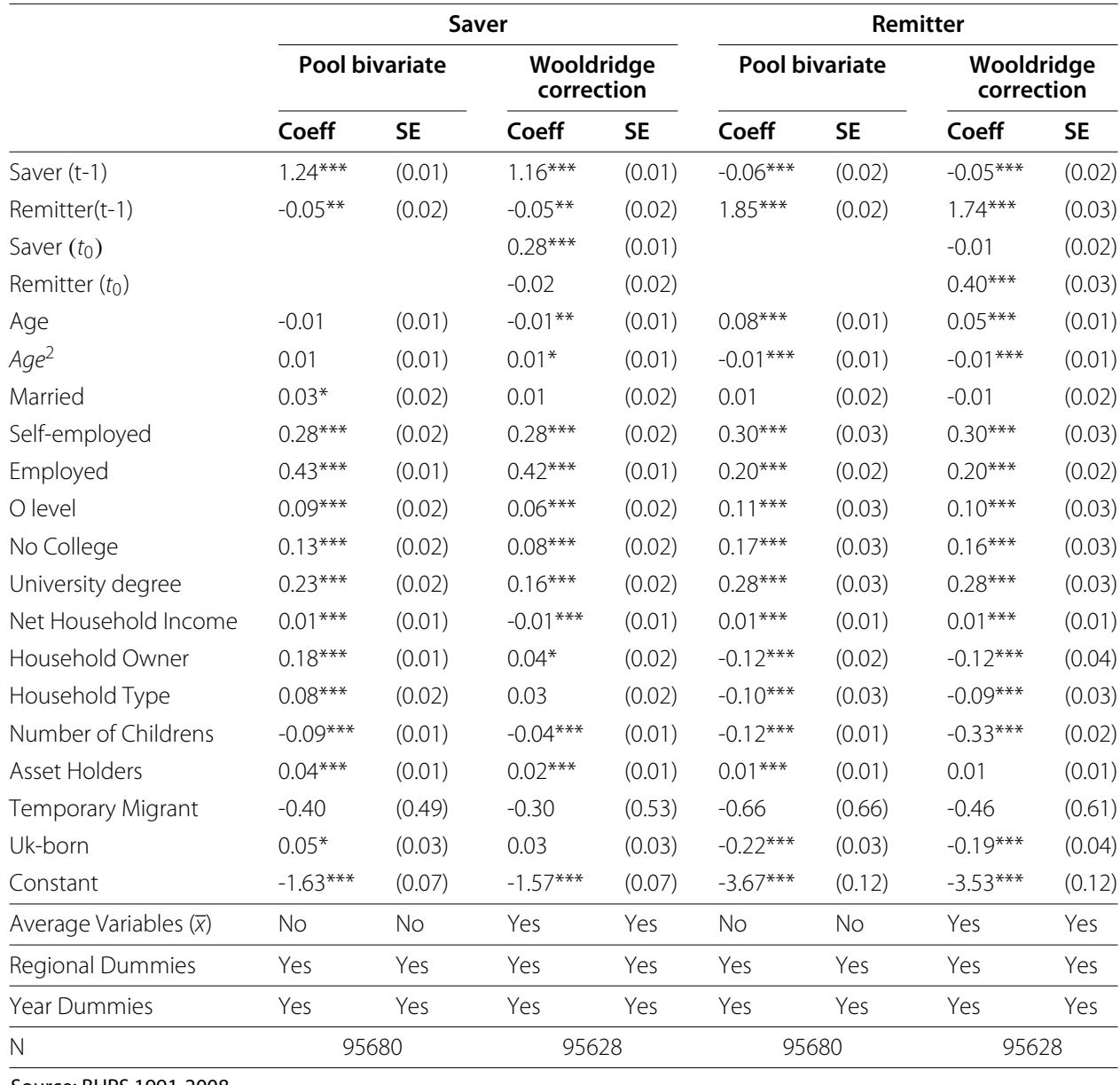


to the problem of the initial conditions, as suggested by Heckman (1981), where the dependent variables (in our case, declaring to save and remit) can be influenced by the other variables, by unobserved individual heterogeneity, and by the presence of correlated lagged endogenous variables.

The initial conditions problem suggested by Heckman (1981) raises an important issue for the estimation of dynamic discrete choice models with dynamics where the unobserved heterogeneity term is correlated with (past values of) the dependent variable. In a static discrete choice model, the problem does not appear, and the strict exogeneity of all the control variables suffices to have consistent and unbiased estimates. In a dynamic setting, the exogeneity of the control variables is difficult to hold and impossible when one of the regressors is a lagged dependent variable.

The Heckman (1981) approach suggests enriching the likelihood function with the reduced form equation for the initial observation and then maximize using the full set of sample observations, allowing for cross-correlation. ${ }^{6}$

The problem of initial conditions occurs when the econometrician deals especially with short panel datasets. For instance, Yu et al. (2008) suggest that the initial conditions problem does not cause any serious bias if the panel consists of 20 waves and over, but the bias is considered significant with panels with 8 waves or less.

In the case of our bivariate model, the presence of the both lagged dependent variables and the correlation with the unobserved individual heterogeneity implies that the Heckman correction is required. Alessie et al. (2004) extends the model proposed by Heckman (1981), initially for a univariate discrete choice model to a bivariate framework, introducing two static equations for $t=1$, which can be seen as a linearized approximation of the reduced form for the latent variable. The Alessie et al. (2004) estimator requires Simulated Maximum Likelihood Estimation.

An alternative framework to account for the initial conditions problem is Wooldridge (2005) who proposes a Conditional Maximum Likelihood (CML) estimator, assuming the distribution conditional to the initial values and to the trace of the observed exogenous variables. Specifically, instead of assuming $\left(y_{i, 1} \ldots y_{i, T}\right)$ modeled on the $x_{i}$ (not necessarily dichotomic), he assumes the distribution of the density $\left(y_{i, 1} \ldots y_{i, T}\right)$ conditional to $\left(y_{i, T}, x_{i}\right)$. Wooldridge restricts the model to the univariate case and specifies the following equation to be estimated:

$$
\alpha_{i}=a_{0}+a_{1} y_{i, 1}+a_{2} \overline{x_{i}}+\epsilon_{i}
$$

where $a_{0}, a_{1}, a_{2}$ are the parameters to be estimated, $\overline{x_{i}}$ are the averaged-over-time values of the control variables, and $\epsilon_{i}$ is distributed as an i.i.d..

Devicienti and Poggi (2011) extend the model proposed by Wooldridge (2005) for the bivariate case using the following specification when using our symbols:

$$
\begin{aligned}
& \alpha_{s, i}=a_{s, 0}+a_{s, s} y_{s, i, 1}+a_{s, r} y_{r, i, 1}+a_{s, x} \overline{x_{i}}+\epsilon_{s, i, 1} \\
& \alpha_{r, i}=a_{r, 0}+a_{r, s} y_{s, i, 1}+a_{r, r} y_{r, i, 1}+a_{r, x} \overline{x_{i}}+\epsilon_{r, i, 1}
\end{aligned}
$$

According to our dataset, $y_{s, i, 1}$ and $y_{r, i, 1}$ are the two initial values of the two dependent variables, i.e., status of saver and status of remitter. By including Equations (5) and (6) 
in the framework of our bivariate model (1)-(3), we get the following equations for the estimation of the model:

$$
\begin{aligned}
& y_{s, i, t}=\beta_{s} x_{i, t}^{\prime}+\lambda_{s, s 1} y_{s, i, t-1}+\lambda_{s, r} y_{r, i, t-1}+a_{s, 0}+a_{s, s} y_{s, i, 1}+a_{s, r} y_{r, i, 1}+a_{s, x} \overline{x_{i}}+\epsilon_{s, i}+u_{s, i, t} \\
& y_{r, i, t}=\beta_{r} x_{i t}^{\prime}+\lambda_{r, s} y_{s, i, t-1}+\lambda_{r, r} y_{r, i, t-1}+a_{r, 0}+a_{r, s} y_{s, i, 1}+a_{r, s} y_{r, i, 1}+a_{r, x} \overline{x_{i}}+\epsilon_{r, i}+u_{r, i, t}
\end{aligned}
$$

Equations (7) and (8) can be estimated with CMSL and will produce consistent estimates. $^{7}$

The estimation of the model proposed by Alessie et al. (2004) requires approaches of numerical integration through simulation of the data through a BFGS algorithm. ${ }^{8}$ We apply the extension proposed by Devicienti and Poggi (2011) using the Wooldridge (2005) method for bivariate estimation because of more efficiency due to our large sample. ${ }^{9}$

The results of our estimation are shown in Table 4 under the columns Wooldridge Correction, whereas the marginal effects are reported in Table 5.

When computing the marginal effects after running the Wooldridge correction, almost all the control variables report highly and significant coefficients (at a 1 percent level of significance) with the expected sign. Employed, self-employed, and individuals with higher levels of education save and remit more with respect to the other categories (unemployed and lower levels of education).

The marginal effects have positive signs for all the occupational categories (the reference category is being unemployed) and level of education (the reference category is college degree). Regarding the self-employed individuals, we detect a relatively high effect with increasing probabilities for both saving and remitting, but it is more intense for the remitter status. Higher educational levels are associated with more savings and remittances at the same time. The probability of saving also increases with net household income and decreases with being a household owner or living with a partner, which are all proxies of integration and longer plans of staying. Significant and positive effects are also shown for demographic characteristics - for instance, the older the people, the higher their amount of savings but not of remittances; meanwhile, married individuals prefer more remittances than savings. Having more children decreases both probabilities. The coefficient that identifies non UK-born shows negative marginal effects for saving and positive effects for remittances. Thus, all migrants (temporary and permanent) will place relatively more remittances then savings.

The main coefficient of interest is the nature of migration (temporary or permanent), and no significant effect was found with the starting bivariate model. However, when the marginal effects are computed and reported in Table 5, the average marginal effects of both status (saving and remitting) are significant at the 1 percent level and negative. The marginal effect of being temporary is significant and negative with respect to being a saver. More precisely, when the decision on migration duration is temporary, the probability of saving decreases by 3 percent. It means that the migrant places a larger amount of remittances than savings in the hosting country. 
Table 5 Marginal effects of the bivariate dynamic model for savers and remitters

\begin{tabular}{|c|c|c|c|c|c|c|}
\hline & (1) & (2) & (3) & (4) & (5) & (6) \\
\hline & p11 & p10 & p01 & p00 & Remitter & Saver \\
\hline \multirow[t]{2}{*}{ Save (t-1) (d) } & $0.015^{* * *}$ & $0.445^{* * *}$ & $-0.020^{* * *}$ & $-0.440^{* * *}$ & $0.460^{* * *}$ & $-0.005^{* * *}$ \\
\hline & $(0.0007)$ & $(0.0039)$ & $(0.0008)$ & $(0.0039)$ & $(0.0039)$ & $(0.0013)$ \\
\hline \multirow[t]{2}{*}{ Remit (t-1) (d) } & $0.182^{* * *}$ & $-0.200^{* * *}$ & $0.270^{* * *}$ & $-0.252^{* * *}$ & $-0.018^{* *}$ & $0.451^{* * *}$ \\
\hline & $(0.0053)$ & $(0.0055)$ & $(0.0064)$ & $(0.0071)$ & $(0.0075)$ & (0.0089) \\
\hline \multirow[t]{2}{*}{ Age } & $0.003^{* * *}$ & $-0.004^{* * *}$ & $0.004^{* * *}$ & $-0.003^{* * *}$ & -0.001 & $0.006^{* * *}$ \\
\hline & $(0.0001)$ & $(0.0011)$ & $(0.0002)$ & $(0.0011)$ & $(0.0011)$ & $(0.0004)$ \\
\hline \multirow[t]{2}{*}{ Agesq } & $-0.001^{* * *}$ & $0.001^{* * *}$ & $-0.001^{* * *}$ & $0.001^{* *}$ & 0.001 & $-0.001^{* * *}$ \\
\hline & $(0.0001)$ & $(0.0001)$ & $(0.0001)$ & $(0.0001)$ & $(0.0001)$ & $(0.0001)$ \\
\hline \multirow[t]{2}{*}{ Married (d) } & 0.004 & $0.011^{*}$ & -0.004 & $-0.015^{*}$ & $0.011^{*}$ & 0.001 \\
\hline & $(0.0008)$ & $(0.0057)$ & $(0.0011)$ & $(0.0058)$ & $(0.0059)$ & $(0.0019)$ \\
\hline \multirow[t]{2}{*}{ Self-employed (d) } & $0.021^{* * *}$ & $0.091^{* * *}$ & $0.011^{* * *}$ & $-0.121^{* * *}$ & $0.111^{* * *}$ & $0.031^{* * *}$ \\
\hline & $(0.0022)$ & $(0.0083)$ & (0.0019) & $(0.0083)$ & $(0.0086)$ & $(0.0039)$ \\
\hline \multirow[t]{2}{*}{ Employ (d) } & $0.013^{* * *}$ & $0.151^{* * *}$ & $0.003^{* * *}$ & $-0.166^{* * *}$ & $0.163^{* * *}$ & $0.016^{* * *}$ \\
\hline & $(0.0007)$ & $(0.0047)$ & $(0.0010)$ & $(0.0049)$ & $(0.0049)$ & $(0.0016)$ \\
\hline \multirow[t]{2}{*}{ O level (d) } & $0.006^{* * *}$ & $0.028^{* * *}$ & $0.004^{* * *}$ & $-0.037^{* * *}$ & $0.033^{* * *}$ & $0.009^{* * *}$ \\
\hline & $(0.0013)$ & $(0.0067)$ & $(0.0015)$ & $(0.0068)$ & $(0.0069)$ & $(0.0027)$ \\
\hline \multirow[t]{2}{*}{ No college degree (d) } & $0.008^{* * *}$ & $0.041^{* * *}$ & $0.006^{* * *}$ & $-0.055^{* * *}$ & $0.049^{* * *}$ & $0.014^{* * *}$ \\
\hline & $(0.0010)$ & $(0.0057)$ & $(0.0012)$ & $(0.0058)$ & $(0.0059)$ & $(0.0021)$ \\
\hline \multirow[t]{2}{*}{ University degree (d) } & $0.016^{* * *}$ & $0.073^{* * *}$ & $0.010^{* * *}$ & $-0.100^{* * *}$ & $0.090^{* * *}$ & $0.026^{* * *}$ \\
\hline & $(0.0018)$ & $(0.0075)$ & $(0.0018)$ & $(0.0076)$ & $(0.0078)$ & $(0.0035)$ \\
\hline \multirow[t]{2}{*}{ Net Household Income } & $0.001^{* * *}$ & $0.004^{* * *}$ & $0.001^{* * *}$ & $-0.005^{* * *}$ & $0.005^{* * *}$ & $0.001^{* * *}$ \\
\hline & $(0.0001)$ & $(0.0002)$ & $(0.0001)$ & $(0.0002)$ & $(0.0002)$ & $(0.0001)$ \\
\hline \multirow[t]{2}{*}{ Household Owner (d) } & $-0.002^{* *}$ & $0.070^{* * *}$ & $-0.009^{* * *}$ & $-0.059^{* * *}$ & $0.068^{* * *}$ & $-0.010^{* * *}$ \\
\hline & $(0.0007)$ & $(0.0048)$ & $(0.0011)$ & $(0.0049)$ & $(0.0050)$ & $(0.0019)$ \\
\hline \multirow[t]{2}{*}{ Household Type (d) } & $-0.002^{*}$ & $0.033^{* * *}$ & $-0.006^{* * *}$ & $-0.025^{* * *}$ & $0.031^{* * *}$ & $-0.008^{* * *}$ \\
\hline & $(0.0012)$ & $(0.0083)$ & $(0.0018)$ & $(0.0084)$ & $(0.0086)$ & $(0.0030)$ \\
\hline \multirow[t]{2}{*}{ Number of Children } & $-0.005^{* * *}$ & $-0.027^{* * *}$ & $-0.004^{* * *}$ & $0.037^{* * *}$ & $-0.033^{* * *}$ & $-0.0101^{* * *}$ \\
\hline & $(0.0004)$ & $(0.002)$ & $(0.0005)$ & $(0.0024)$ & $(0.0024)$ & $(0.0009)$ \\
\hline \multirow[t]{2}{*}{ Asset Holders } & $0.001^{* * *}$ & $0.013^{* * *}$ & 0.001 & $-0.014^{* * *}$ & $0.014^{* * *}$ & $0.001^{* * *}$ \\
\hline & $(0.0001)$ & $(0.0021)$ & $(0.0002)$ & $(0.0021)$ & $(0.0022)$ & $(0.00032)$ \\
\hline \multirow[t]{2}{*}{ Temporary Migrant (d) } & $-0.014^{* * *}$ & -0.132 & -0.016 & 0.162 & -0.146 & $-0.030^{* *}$ \\
\hline & $(0.0037)$ & $(0.161)$ & $(0.0100)$ & $(0.1570)$ & $(0.1610)$ & $(0.0135)$ \\
\hline \multirow[t]{2}{*}{ Uk-born (d) } & $-0.008^{* * *}$ & $0.028^{* * *}$ & $-0.013^{* * *}$ & -0.005 & $0.019^{*}$ & $-0.022^{* * *}$ \\
\hline & $(0.0018)$ & (0.0106) & $(0.0024)$ & (0.0109) & $(0.0112)$ & $(0.0040)$ \\
\hline
\end{tabular}

Marginal effects; Standard errors in parentheses.

(d) for discrete change of dummy variable from 0 to 1 .

${ }^{*} p<0.10$, ${ }^{* *} p<0.05,{ }^{* * *} p<0.01$.

\section{Savings of temporary and permanent migrants vs natives and their financial capability}

As mentioned above, the life-cycle theory predicts that migrants should save more than natives if their expectation of future income is lower. However, the saving choice depends on many different dimensions other than current income, and in this section, we investigate the importance of various socio-economic variables in determining the difference between natives' and migrants' saving behavior. In particular, we build an index of financial capability adjusted for income in order to highlight the importance of all the factors, besides income, that can play a role in the saving choices of natives and migrants. 


\subsection{The index of financial capability}

Although the capability of saving is mainly constrained by economic indicators like income and wealth, many other socio-economic variables play an important role in the saving choice. Some of these variables are easily observable - like the education level but many others are more difficult to measure and to quantify, although important in the saving decision - for instance, the degree of trust in the financial system, the psychological attitude towards savings, etc. Cultural and psychological factors are quite important when assessing the capability of saving and of managing financial assets (see, for instance, Atkinson et al. 2006).

The concept of financial (in)capability involves general economic knowledge and particular skills that may induce saving or investment in financial assets, but is determined also by general psychological attributes, although unobservable.

Recent studies have analyzed the concept of financial capability relating it to psychological well-being (as in Taylor et al. 2011) or to consumer behavior (as in Atkinson et al. 2006).

The research conducted by Taylor et al. (2011) introduces the concept of financial capability with an index as the sum of the scores of four groups of variables and involving multivariate analysis. Using data from BHPS, they found that financial and psychological well-being are highly correlated with the financial capability index. They find that greater financial incapability is instead associated with greater mental stress, lower life satisfaction, and reported health problems (like anxiety or depression).

The consumer market research proposed by Atkinson et al. (2006) underlines the results of a baseline survey in UK assessing the concept of financial well-being and financial capability. They propose a factor analysis across the four domains from which they create five separate scores for each respondent. The first two scores relate to different aspects of the first domain - managing money - meanwhile, the other three scores relate to three separate domains - planning ahead, choosing products, and staying informed. They obtain scores within each area and conclude that older people, people with higher incomes, and those in couples with no dependent children have the greatest financial capability, while younger people, people in couples with dependent children, single people, and those with lower income have lower capability.

Using factor analysis, we propose an index of financial incapability for the two groups of our interest - natives and migrants - by following the method proposed by Taylor et al. (2011).

We use three domains of different variables that capture the multidimensional environment of the index and calculate a score index for each individual among migrants and natives. The three domains of variables are a) Perceived Financial Situation, b) Financial Expectations, and c) Financial Situation changed. Each of the three domains use the answers to the different questions of the BHPS (see the last three parts in Table 2 where we reported the summary statistics).

A Spearman rank correlation test is also performed for all 9 variables. ${ }^{10}$ Indeed, the index is computed by the multivariate approach of factor analysis and using the correlations between variables in order to determine the underlying factor representing financial capability (see Taylor et al. 2011).

We regress the factors produced by the multivariate approach on net household income (household income divided by the number of members in the household) in order to 
obtain an indicator adjusted by income. As the result of this orthogonalization, the index captures the heterogeneity due to financial capability aside from household income.

This index is shown in Figure 3 and is normalized to take values in the interval $[-1,1]$ (with the mean 0.0001 and standard deviation equal to 0.14). Figure 3(a) shows the kernel density of the index for the two subgroups of the population, whereas in Figure 3(b), we show the correlation of the constructed index with the amount of savings for the two subgroups of the populations. As is evident in the graphs, there is stochastic dominance of the natives for all the distributions. Figure 3(a) shows that natives have relatively higher density around the zero mean. Figure 3 (b) reports that the amount of savings decreases

(a) Density Distribution: Index of Financial Incapability

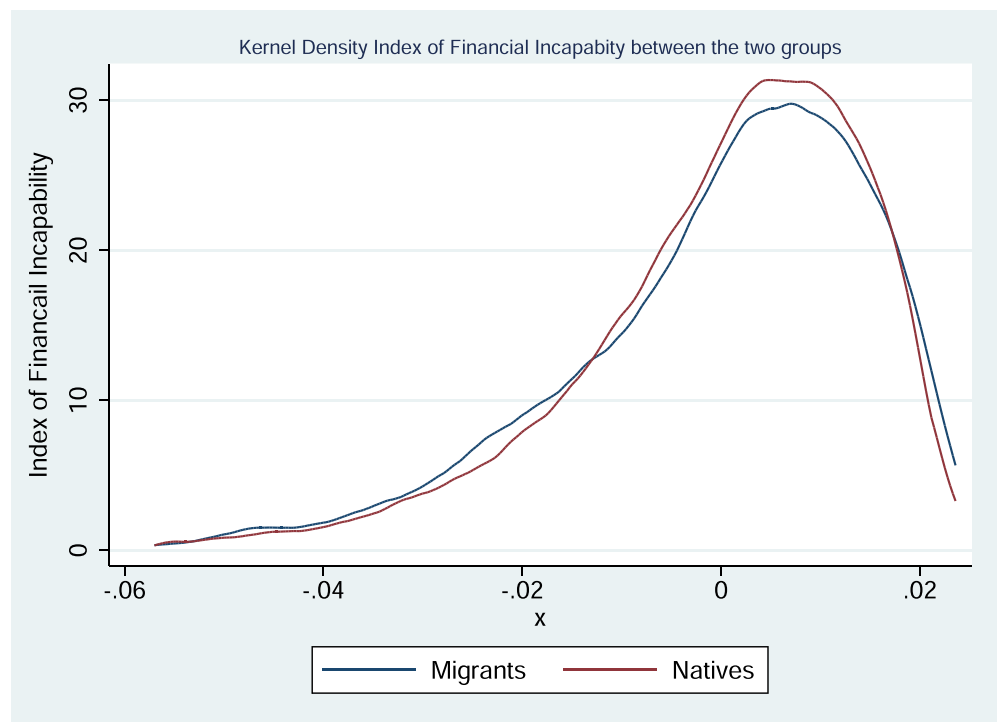

(b) Correlation between Savings and Index Financial Incapability

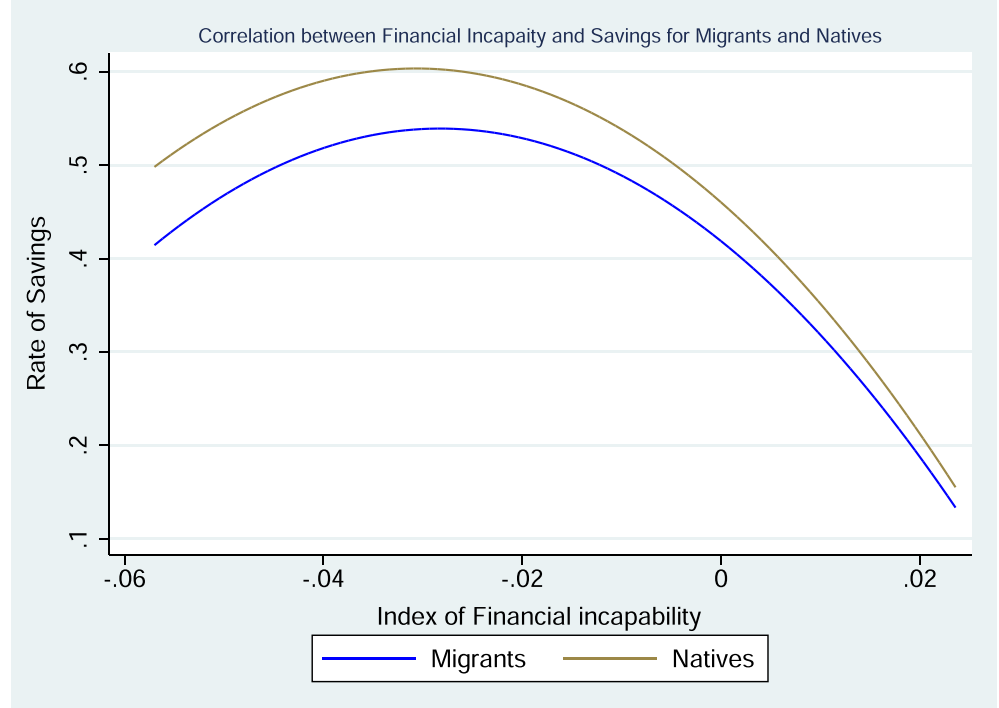

Figure 3 Index of financial incapability and savings. (a) Density distribution: index of financial incapability. (b) Correlation between savings and index financial incapability. 
when financial incapability increases (with some nonlinear effects for negative values of the index), but it is always higher for natives.

\subsection{Temporary and permanent migrants: estimation of the saving equation}

Our study aims at analyzing the saving behavior of migrants (temporary and permanent) and natives by taking into account observed variables and good proxies of unobserved variables. The idea is to uncover the characteristics or social-economic variables that would explain the different saving profiles between natives and migrants.

When using data from the German Panel (GOESP), Bauer and Sinning (2011) found that permanent migrants in Germany save relatively less than the natives, and this is due mainly to the differences in current and permanent income, suggesting that permanent migrants might not have the capacity to save as much as native households because of solely economic reasons.

The summary statistics shown in Table 2 report a very high percentage of individuals declaring "not saving monthly". This percentage is slightly different for the two groups: 61 percent of migrants and 58 percent of natives report no monthly savings.

When using highly censored data, OLS estimation provides inconsistent estimates of parameters, and a standard censored Tobit model would fit better with our data. Two separate equations for the two groups (natives $n$ and migrants $m$ ) are estimated so as to allow for a further decomposition analysis. ${ }^{11}$ The equations can be written as an index function in the following way:

$$
S_{i, t, j}^{*}=X_{i, t, j} \beta_{j}+\epsilon_{i, t, j} \text {, where }
$$

$S_{i, t, j}=0$ if $S_{i, t, j}^{*} \leq 0$

$S_{i, t, j}=S_{i, t, j}^{*}$ if $S_{i, t, j} *>0$ for $i=1 \ldots . . N$ and $t=1 \ldots . . T$ and $j=m, n$

The unconditional expected value of savings $S_{i, t, j}$ for individual $i$ at time $t$ and belonging to group $j$ equals the probability of $S_{i, t, j}$ being uncensored and the expectation of $S_{i, t, j}$ given positive savings (the conditional expectation).

The estimated equation is the following: ${ }^{12}$

$$
\begin{aligned}
E\left(S_{i, t, j} \mid X_{i, t, j}\right) & =P\left(S_{i, t, j}>0 \mid X_{i, t, j}\right) E\left(S_{i, t, j} \mid S_{i, t, j}>0, X_{i, t, j}\right) \\
& =\Phi\left(\frac{X_{i, t, j} \xi_{j}}{\beta_{j}}\right) X_{i, t, j} \xi_{j}+\beta_{j} \phi\left(\frac{X_{i, t, j} \xi}{\beta j}\right),
\end{aligned}
$$

where $\phi(\cdot)$ represents the normal density function and $\Phi(\cdot)$ is the normal distribution function; the two parameters to estimate by the Maximum Likelihood are the coefficients in $\beta_{j}$ and the standard deviations in $\xi_{j}$ for each group $j=m, n$.

The results of the Tobit model with and without the index are shown in Table 6 when considering only the subsample of all migrants, but distinguishing between temporary and permanent migrants. ${ }^{13}$ The dependent variable is the amount of monthly savings, and this also includes remittances in the case of migrants.

We ought to notice the negative effects of the financial incapability index on the amount of savings: the coefficient is negative and significant at the 1 percent significance level. All the other control variables have the expected sign; for instance, the high education level, as a University degree, has a positive sign, and it is significant at the 1 percent level. Three dummy variables for education and household characteristics are also included along with regional and yearly dummies. 
Table 6 Tobit estimation for amount of savings (logarithm)

\begin{tabular}{|c|c|c|}
\hline & (1) & (2) \\
\hline & Coeff/SE & Coeff/SE \\
\hline \multirow[t]{2}{*}{ Age } & 0001 & -0010 \\
\hline & $(0006)$ & (0008) \\
\hline \multirow[t]{2}{*}{ Agesq } & -0001 & 0001 \\
\hline & $(0001)$ & $(0001)$ \\
\hline \multirow[t]{2}{*}{ Male } & $-0080^{* * *}$ & -0077 \\
\hline & $(00231)$ & 00226 \\
\hline \multirow[t]{2}{*}{ Married } & -0049 & 0008 \\
\hline & (0010) & $(0037)$ \\
\hline \multirow[t]{2}{*}{ Self Employed } & $0260^{* * *}$ & $0300^{* * *}$ \\
\hline & $((0049))$ & $(0053)$ \\
\hline \multirow[t]{2}{*}{ Employed } & $0201^{* * *}$ & $0192^{* * *}$ \\
\hline & $(0008)$ & $(0036)$ \\
\hline \multirow[t]{2}{*}{ Unemployed } & 0072 & 0093 \\
\hline & $(0010)$ & $(0087)$ \\
\hline \multirow[t]{2}{*}{ O Level } & -0018 & -0017 \\
\hline & $(0050)$ & $(0066)$ \\
\hline \multirow[t]{2}{*}{ No College } & 0057 & 0038 \\
\hline & (0039) & $(0052)$ \\
\hline \multirow[t]{2}{*}{ University Degree } & $0245^{* * *}$ & $0192^{* * *}$ \\
\hline & $(0045)$ & $(0055)$ \\
\hline \multirow[t]{2}{*}{ HouseOwner } & -0020 & -0046 \\
\hline & $(0010)$ & (0034) \\
\hline \multirow[t]{2}{*}{ Household Type } & -0005 & -0056 \\
\hline & (0013) & (0053) \\
\hline \multirow[t]{2}{*}{ Assets Holding $\times 10^{2}$} & $0004^{* * *}$ & $0001^{* * *}$ \\
\hline & $(0040)$ & $(0001)$ \\
\hline \multirow[t]{2}{*}{ Index of Financial Incapability } & - & $-5423^{* * *}$ \\
\hline & & (0796) \\
\hline \multirow[t]{2}{*}{ Temporary } & 0095 & $0260^{*}$ \\
\hline & $(0179)$ & $(0142)$ \\
\hline \multirow[t]{2}{*}{ Constant } & $2082^{* * *}$ & $2161^{* * *}$ \\
\hline & (0299) & (0174) \\
\hline \multirow[t]{2}{*}{$\sigma_{u}$} & $0306^{* * *}$ & \\
\hline & & (0014) \\
\hline \multirow[t]{2}{*}{$\sigma_{e}$} & $0300^{* * *}$ & \\
\hline & & (0006) \\
\hline $\mathrm{N}$ & 1562 & 1562 \\
\hline
\end{tabular}

Differently from the evidence in Section 3, the difference between permanent and temporary migrants is now positive at common significance levels as expected by theoretical prediction. The dummy for temporary migrants is significant at the 10 percent level for the Tobit estimation, and shows that the amount of savings will increase by 26 percent.

\subsection{Migrants vs. natives: non-linear decomposition model}

A second type of analysis regards a comparison between migrants and natives by disentangling the difference between the two groups as a difference due to structural 
parameters (i.e., a different propensity to save) and due to explanatory variables (i.e., different income levels or financial capability). We make use of the decomposition model proposed by Blinder (1973) and Oaxaca (1973).

Originally, Blinder (1973) and Oaxaca (1973) analyzed the wage gap between males and females. By following a linear decomposition method, their method allows for the decomposition of the difference in an outcome variable between two groups into one portion explained by differences in the observed characteristics and a second part due to differences in the estimated coefficients.

In our case, we cannot use a linear decomposition model due to the large number of individuals who do not save at all and need to extend the method to the Tobit model by following the suggestion of Bauer and Sinning (2010). The decomposition is then as follows:

$$
\begin{aligned}
\Delta_{m, n}^{T o b i t} \equiv & E_{\xi_{n}, \beta_{n}}\left(S_{i, t, n} \mid X_{i, t, n}\right)-E_{\xi_{m}, \beta_{m}}\left(S_{i, t, m} \mid X_{i, t, m}\right) \\
= & {\left[E_{\xi_{n}, \beta_{n}}\left(S_{i, t, n} \mid X_{i, t, n}\right)-E_{\xi_{n}, \beta_{m}}\left(S_{i, t, m} \mid X_{i, t, m}\right)\right] } \\
& +\left[E_{\xi_{n}, \beta_{m}}\left(S_{i, t, m} \mid X_{i, t, m}\right)-E_{\xi_{m}, \beta_{m}}\left(S_{i, t, m} \mid X_{i, t, m}\right)\right]
\end{aligned}
$$

The estimation of equation (10) will make use of the Maximum Likelihood function shown for (9).

Similar to the decomposition equation of the linear model, the calculation of the counterfactual parts of (10), is based on the average characteristics and the estimated coefficients and error variance of the two groups, natives and migrants. The idea is to decompose the difference in the estimated conditional savings of the two groups into a component that represents the change in the expected savings rate of the households with positive savings, weighed by the probability of having a positive savings rate, and into a component that represents the change in the probability of positive savings, weighed by the expected value of savings if savings are positive (see Bauer and Sinning 2011).

The estimated regressions for migrants and natives (not shown) are decomposed as proposed by equation (10), and the results are reported in Table 7.

The first part of the Table shows the results of the decomposition of the censored dependent variable through Tobit without including the index of financial (in)capability. This indicates that nearly 45 percent of the saving differential between migrant and natives is attributable to differences in observable characteristics, whereas the 50 percent is due to unobservable variables.

The results of the Tobit decomposition, when including the index, show that almost 95 percent of the differences is due to observable and only 5 percent of the differences between natives and migrants is not explained. This means that all the characteristics represented by the control variables used in the regressions shown in Table 6 can actually explain the differences in the saving patterns between natives and migrants, but the increase in the goodness of fit is produced mostly by our index.

When considering the remittances as savings, the results remain robust to the first decomposition when considering only savings as independent variable. The increase in the goodness of fit in this case is higher, as in this case, remittances may be attributed only to migrants and not for natives. The percentage that explains the differences in the characteristics in this case is around 99 percent and only 1 percent can be attributed to the estimated coefficients. 
Table 7 Decomposition mode for Tobit: natives vs migrants

\begin{tabular}{lcc}
\hline Savings & Natives vs. Migrants-without index & Natives vs. Migrants -with index \\
\hline$\widehat{\Delta}^{\text {Tobit }}$ & 0.29 & $-2.029^{* *}$ \\
& $(0.404)$ & $(1.027)$ \\
Explained part & 0.014 & $-2.038^{* *}$ \\
& $(0.040)$ & $(1.030)$ \\
in \% of $\widehat{\Delta}^{\text {Tobit }}$ & {$[49.94]$} & {$[95.46]$} \\
Unexplained part & 0.015 & 0.092 \\
& $(0.0096)$ & $(0.087)$ \\
in \% of $\widehat{\Delta}^{\text {Tobit }}$ & {$[50.06]$} & {$[4.54]$} \\
\hline Savings+Remittances & Natives vs. Migrants-without index & Natives vs. Migrants -with index \\
\hline$\widehat{\Delta}^{\text {Tobit }}$ & 0.066 & $-4.70^{* * *}$ \\
& $(1.28)$ & $(2.35)$ \\
Explained part & 0.033 & $-4.72^{* * *}$ \\
& $(1.29)$ & $(2.36)$ \\
in \% of $\widehat{\Delta}^{\text {Tobit }}$ & {$[38.91]$} & {$[99.01]$} \\
Unexplained part & 0.033 & 0.015 \\
& $(0.023)$ & $(0.018)$ \\
in \% of $\widehat{\Delta}^{\text {Tobit }}$ & {$[61.09]$} & {$[0.9]$} \\
\hline ***Comparison between the decomposition without Index of Financial Incapability and then Including the Index of \\
Financial Incapability Logarithm of savings; in both cases decomposed Bootstrap (50) replications; standard errors in \\
parenthesis. Number of observations: Group (A) $=42213 ;$ Group (B)=1562.
\end{tabular}

\section{Conclusions}

This paper explored the saving behavior across immigrants using a long panel of micro data, the British Household Panel Survey (1991-2008). The hypothesis underlying the empirical investigation derives from theoretical predictions where migrants are supposed to save more in case their migration plans are temporary. The estimation results show that in the case of temporary migrants, the propensity to save will increase by 26 percent in comparison with those who stay permanently in UK. These results are shown to be robust using a bivariate probability model in a dynamic setting where the savings and remittances are considered as binary choices.

As mentioned in the Introduction, many countries show the tendency to prefer temporary versus permanent migrants for the expected negative consequences on natives in the domestic labor markets. Our evidence shows another consequence of this preference in migration policy. Temporary migrants tend to save more and therefore contribute less to the aggregate demand of domestic goods, which may be less desirable when recessions are characterized by low aggregate demand (as in Europe after the financial crisis).

Moreover, temporary migrants tend not only to save more, but also to remit more. Hence, this favors a leakage of domestically produced savings towards the origin country. Many temporary migrants actually end up staying longer than expected, and the ex-post difference between temporary and permanent migrants is more blurred than expected. But if temporary migrants acted as if they were to return home (i.e., saving and remitting more) but instead overstay, the miscalculation of their life-cycle wealth may become an additional burden for the destination countries.

The second piece of evidence regards the differences in the saving patterns between migrants and natives by using the Blinder-Oaxaca decomposition for a Tobit model of saving decisions. In particular, we have introduced an index of financial capability adjusted 
for income, and the decomposition analysis shows that the difference in the savings profiles between natives and migrants may be greatly explained by observable socialeconomic characteristics only when projecting in the space spanned also by the index of financial (in)capability. In other words, our results show that migrants' socio-economic characteristics have a different weight in explaining the dissimilar saving behavior with respect to natives, but the the financial condition plays a determinant role that overcomes many possible cultural differences between natives and migrants.

Therefore, a relevant message for migration policy interventions is to take into great consideration the economic and financial conditions of migrants' households when the objective is integration and assimilation.

\section{Endnotes}

${ }^{1}$ See, for instance, Avato et al. (2010).

${ }^{2}$ See Blinder (1973) and Oaxaca (1973) for the cited decomposition.

${ }^{3}$ The discrete variable RFINLOC reports whether the sample member remained at the same address as the year before and assigns different codes depending on the different, alternative detected status. For further details, see the BHPS Documentation, ISER, University of Essex.

${ }^{4}$ Alessie et al. (2004) also discusses the special case when $\lambda_{s, r}=0$ and $\lambda_{r, s}=0$ and the two Equations (1) and (2) become two separate univariate dynamic probit models whose only link is the error correlation.

${ }^{5}$ The last assumption implies that $x_{i t}$ are strictly exogenous. The uncorrelation of individual effects with the other variables is a strong assumption, but we rely on Alessie et al. (2004), who compares the results of a similar model with a Linear Probability Model for both variables.

${ }^{6}$ Let us recall that the period-zero equation cannot include the lagged dependent variables since they are non-existent. The coefficients obtained are different from the coefficients in the next-period's dynamic equations, whereas the random effects are linear combinations of the random effects. In this way, the error terms are likely to have a particular covariance structure. See Heckman (1981).

${ }^{7}$ The simulation is performed in STATA using the Devicienti and Poggi (2011) model for the estimation of the parameters. The initial values are drawn using 2RN Halton draws as suggested by Train (2003).

${ }^{8}$ See Alessie et al. (2004).

${ }^{9}$ The main reason of this choice is the size of the sample to be simulated. The Alessie et al. (2004) model fits better only for the panel with less than 40,000 observations, whereas the Wooldridge (2005) estimator performs better for larger sample sizes. We recall that the sample size of our panel is 180,543 year-person observations.

${ }^{10}$ Available upon request by the authors.

${ }^{11}$ We then also consider remittances as savings, summing the amount of remittances with saving.

${ }^{12}$ See also Bauer and Sinning (2010).

${ }^{13}$ The estimation for natives is used for the decomposition model. It is not reported in the text, but is available upon request. 


\section{Acknowledgements}

We wish to thank Luisa Corrado, David McKenzie, Erwin Tiongson, an anonymous referee and seminar participants at the University of Rome 2 Tor Vergata and at the ITSG 2014 Conference in Cagliari for useful suggestions on earlier versions of this paper. The usual disclaimer applies.

Responsible editor: Denis Fougere

\section{Author details}

${ }^{1}$ Dept. of Social Sciences and Economics, Political Science Building CU002 - room 103bis, Sapienza University of Rome, P.le Aldo Moro, 5 00185, Rome, Italy. ${ }^{2}$ CREA - University of Luxemburg, Campus Limpertsberg, Bâtiment de Recherche C, 148, avenue de la Faïencerie, L-1511 Luxembourg-Limpertsberg.

Received: 2 February 2015 Accepted: 13 April 2015

Published online: 12 June 2015

\section{References}

Alessie R, Hochguertel S, van Soest A (2004) Ownership of stocks and mutual funds: A panel data analysis. Rev Econ Stat 86(3):783-796

Atkinson A, McKay S, Kempson E, Collard S (2006) Levels of financial capability in the UK: Results of a baseline survey. Financial Services Authority, London

Avato J, Koettl J, Sabates-Wheeler R (2010) Social security regimes, global estimates, and good practices: The status of social protection for international migrants. World Dev 38(4):455-466

Bauer T, Sinning M (2010) Blinder-oaxaca decomposition for tobit models. Appl Econ 42(12):1569-1575

Bauer T, Sinning M (2011) The savings behavior of temporary and permanent migrants in germany. J Popul Econ 24(2):421-449

Bauer T, Zimmermann KF (2000) Immigration policy in integrated national economies. IZA Working Paper No 170

Blinder AS (1973) Wage discrimination: Reduced form and structural estimates. J Hum Res 8(4):436-455

Borjas GJ (1995) Assimilation and changes in cohort quality revisited: What happened to immigrant earnings in the 1980s $J$ Labor Econ 13(2):201-245

Carroll CD, Rhee B-K, Rhee C (1994) Are there cultural effects on saving? some cross-sectional evidence. Q J Econ 109(3):685-699

Cobb-Clark DA, Hildebrand V (2003) The wealth and asset holdings of U.S.-born and foreign-born households: Evidence from sipp data. SEDAP Research Paper No. 89

Constant A, Zimmermann K (2005) Immigrant performance and selective immigration policy: A european perspective. Nat Inst Econ Rev 194(1):94-105

Devicienti F, Poggi A (2011) Poverty and social exclusion: two sides of the same coin or dynamically interrelated processes Appl Econ 43(25):3549-3571

Djajic S, Michael MS (2009) Temporary migration policies and welfare of the host and source countries: A game-theoretic approach. CESifo Working Paper Series 2811, 2009

Djajic S, Milbourne R (1988) An equilibrium model of guest-worker migration. J Int Economics 25(3-4):335-351

Dustmann C (1997) Return migration, uncertainty and precautionary savings. J Dev Econ 52(2):295-316

Dustmann C (2003) Return migration, wage differentials, and the optimal migration duration. European Economic Review, Elsevier, vol. 47(2), pages 353-369, April.

Dustmann C, Mestres J (2010) Savings, asset holdings, and temporary migration. Annales d'Economie et de Statistique 97/98,289-306

Galor O, Stark O (1990) Migrants' savings, the probability of return migration and migrants' performance. Int Econ Rev 31(2):463-467

Heckman JJ (1981) Heterogeneity and state dependence. National Bureau of Economic Research, Inc

Kirdar MG (2009) Labor market outcomes, savings accumulation, and return migration. Labour Econ 16(4):418-428

Merkle L, Zimmermann KF (1992) Savings, remittances, and return migration. Econ Lett 38(1):77-81

Mesnard A (2004) Temporary migration and capital market imperfections. Oxf Econ Papers 56(2):242-262

Oaxaca R (1973) Male-female wage differentials in urban labor markets. Int Econ Rev 14(3):693-709

Peri G (2012) The effect of immigration on productivity: Evidence from u.s. states. Rev Econ Stat 94(1):348-358

Piore MJ (1979) Birds of Passage. Online economics textbooks. Cambridge University Press

Rapoport H, Docquier F (2006) The Economics of Migrants' Remittances, volume 1 of Handbook on the Economics of Giving, Reciprocity and Altruism chapter 17. Elsevier

Stark O, Lucas REB (1988) Migration, remittances, and the family. Econ Dev Cult Change 36(3):465-481

Taylor M, Brice J, Buck N, Prentice-Lane E (2002) British household panel survey user manual. In: Technical report. University of Essex, Colchester

Taylor M, Jenkins SP, Sacker A (2011) Financial capability and psychological health. J Econ Psychol 32(5):710-723

Train K (2003) Discrete Choice Methods with Simulation. In: Number emetr2 in Online economics textbooks. Department of Economics, SUNY-Oswego

Wooldridge JM (2005) Simple solutions to the initial conditions problem in dynamic, nonlinear panel data models with unobserved heterogeneity. J Appl Econometrics 20(1):39-54

Yang D (2006) Why do migrants return to poor countries? evidence from philippine migrants' responses to exchange rate shocks. Rev Econ Stat 88(4):715-735

Yu J, de Jong R, Lee L-f (2008) Quasi-maximum likelihood estimators for spatial dynamic panel data with fixed effects when both $n$ and $t$ are large. J Econometrics 146(1):118-134 